\title{
Emilian Mihailov \\ 6 Refocusing the Nudge Debate on Organ Donation
}

\subsection{Introduction}

In ideal circumstances, five patients can be saved by organ transplantation from just one deceased donor. Thus, a much smaller number of donors compared with the number of patients would solve the medical need. However, in the real world, there is severe organ shortage. On average, 16 patients die every day waiting for the organs they need (Health-EU Newsletter 183). There are many proposals to improve organ availability, from changing practices regarding end-of-life care to supporting cuttingedge research into interspecies chimeras. Improvements could be seen if patients are given the choice to donate their organs in the event of withdrawal of life support in intensive care or assisted suicide (Wilkinson and Savulescu 2012; Shaw 2014). Recent developments in gene editing might allow human organ generation in animals whose organ size, anatomy, and physiology are closer to humans (Wu et al. 2017).

But the most entertained policy change is the shift from an opt-in system to an opt-out system of organ donation, because it promises a big impact at the cost of small changes (Thaler and Sunstein 2009; Halpern 2016). Switching the status quo from registering into a potential donor list to registering out of a potential donor list, is expected to bring significant increases in donation rates. In opt-in systems, people have to act themselves, thus spending time and other resources, to register. In opt-out systems, people are presumed potential donors by default. If they wish to donate, they just do nothing. If they do not wish so, then they could actively express their unwillingness. This contrast is framed as informed, explicit, or positive consent versus presumed or implicit consent.

The shift toward presumed donorship is inspired by research on nudges from behavioral sciences. A nudge is a particular design on how people's possible choices are arranged. We nudge someone when we set up his/her choice context so as to increase the likelihood of picking choice (A) over choice (B), even though it would still be easy to choose (B). For example, if we want to increase the consumption of a food item, we display it at the eye level, while other products will be displayed last. Private companies nudge clients all the time, but governments have started to do this as well. The most famous examples are the nudge units inside the US and UK governments, which draw on social and behavioral sciences to influence people's decisions in directions considered by themselves better off or conducive to preserving public goods (Sunstein 2014; Halpern 2016). These teams of social scientists identify low-cost policy tools to nudge people to make more savings, eat healthier, or reduce pollution. Proponents of nudging as means of increasing organ donation point to 
huge differences in consent rates between policies that presume people to be donors and policies that do not. The promise of nudging to meet the medical need of patients with organ failure can explain why so many countries are increasingly attracted to opt-out legislation.

Nevertheless, the insistence on influencing people into preferring the status quo of a potential donor has been met with critical reactions of curtailing people's autonomy (MacKay and Robinson 2016; Rodriguez-Arias and Morgan 2016). Although the opt-out policy appeals to consent language, it may undermine the standard of autonomy asserted by explicit consent. As Janet Radcliffe Richards puts it, "If you think we should accept as a fundamental right that organs should not be used without positive consent, that in itself settles the question. (...) On the other hand, if you do not think there should be such a principle, the question about policy remains open" $(2013,155)$.

In this paper, I argue for refocusing the nudging potential to increase organ donation as it is not inherently opposed to consent standards. The debate is too much focused on a type of intervention that raises worries about respecting people's autonomy and does not have a great-sized effect to justify the insistence on opt-out schemes. As I will show, nudges are versatile enough in their modus operandi to mitigate concerns about respect for autonomy and have a much wider application. Firstly, I present what motivates policymakers to push for opt-out legislation. Then I will make the case for a more realistic picture about the impact of such systems, downplaying their attraction. Thirdly, I will argue that the current opt-out legislation is based on dubious usage of consent standards and that the nudging potential can be refocused within the framework of explicit consent. In the end, I will further suggest how behavioral interventions can be rerouted to have a wider application. We can also nudge pivotal stakeholders such as family members and medical professionals who act on behalf of public institutions, not only potential donors.

\subsection{The success of opt-out systems}

In general, people are willing to help. A recent poll shows that $95 \%$ of Americans strongly support organ donation (National Survey of Organ Donation Attitudes and Behaviors 2013). According to a wide public opinion report in 2009, 55\% of Europeans are willing to donate one of their organs to an organ donation service immediately after death (Special Eurobarometer 333a 2010). If we break down these results by individual countries, some show even greater support. In countries such as Sweden, Malta, Belgium, Finland, and Denmark, $>70 \%$ are willing to donate. The gap between support and action poses serious challenges to policymaking.

What kind of measures are effective in moving people from approval to action? In answering this difficult empirical question, the fact that there are huge differences in the number of registrations between countries is often pointed out. Why are only $28 \%$ 
of Americans but $99.9 \%$ of French citizens registered as donors? Why are only $4.25 \%$ of Danish citizens but $85.6 \%$ of Swedes registered as donors, especially since both strongly support organ donation? It is not very convincing to think, as Gigerenzer puts it, that Americans are "more anxious about a post-mortem opening of their bodies than the French" (2008, 2). As previously highlighted, attitude surveys do show a generalized willingness to donate.

These numbers are better explained by differences in default positions. In Hungary, France, and Sweden, the policy default is that everyone is presumed to be a donor, whereas in Denmark, the US, and England, the default is that nobody is presumed to be a donor. Thus, in opt-out systems, people have to explicitly express their preference not to donate and in opt-in systems, they have to explicitly express their preference to donate. What is at work here is the behavioral rule: "If there is a default, do nothing about it" (Gigerenzer 2008). This rule can be overridden if preferences count against it and the costs are low. Only $0.1 \%$ of French citizens and $0.075 \%$ of Polish citizens opted out from donor default, which might indicate that for many, there is almost no preference against having donor status. Only $17 \%$ of British citizens opted out from nondonor default. This could indicate that only those with strong preferences of becoming donors did something about it. If people do not bother that much to alter a default, then probably not too many will sign a donor card when they are nondonors by default and not too many will do something to become nondonors. It seems that defaults can influence choices in at least two ways (Johnson and Goldstein 2003). On the one hand, defaults can be perceived as reasonable recommendations to save human lives, and, on the other hand, accepting a default is effortless. Depending on the specifics of registration, an active decision can be unpleasant and time consuming. ${ }^{1}$

In their famous study, Johnson and Goldstein (2003) confirmed the powerful effect of defaults on agreement rates. They asked participants whether they would be donors, varying defaults in framing the questions. In the opt-in condition, participants entertained the scenario that they moved to a new country where the default was to be nondonor, and they were given a choice to confirm or change that status. In the opt-out condition, the wording was identical but the choice was to confirm or change the status of donor. In the neutral condition, subjects had to choose with no prior default. The results showed the highest donation rates for the opting-out condition, almost twice as high (82\%) in comparison with the opting-in condition (42\%). Even the neutral condition was significantly higher (79\%) than the nondonor default. ${ }^{2}$

1 In Romania, for instance, the process is burdensome. Firstly, one has to notarize a donation agreement, and then file identification data, as well as data about the notary who attested the donation agreement, to the National Register of Donors (Ministry of Health Order 1158/2012).

2 The results were replicated by Vladucu et al. (2016), showing the highest rates for the opting-out condition, followed by the neutral condition. 
Recently, an opt-out law came into force in Wales, providing a positive case for default effects. Of the 60 organs transplanted between December 2015 and June 2016, half came from people who had not objected to opt out. In the same period in 2014-2015, before the law came into force, 23 people donated their organs, while in 2013-2014, only 21 donated. ${ }^{3}$ More generally, Abadie and Gay (2006) analyzed the impact of opt-out legislation in 22 countries over a 10-year period. After controlling for other factors that contribute to organ donation, they found that switching from opt-in to opt-out systems increases donation rate by approximately $16 \% .{ }^{4}$ Similarly, Shepherd et al. (2014), analyzing a much bigger sample of 48 countries (23 opt-in and 25 opt-out models) over a 12-year period, found that overall opt-out consent is associated with greater deceased donor rates. Considering this potential to increase donation, many medical associations and government representatives have called for opt-out legislation.

\subsection{Tempering the opt-out enthusiasm}

It is understandably tempting to highlight huge differences in donation agreements, which are mainly due to fairly simple changes in default status. What should we prefer: a policy with an impact of $20 \%$ registered donors, or one with over $85 \%$ ? When the choice is framed in this way, the answer is obvious.

Indeed, default policies increase the number of registered donors, but to have an impact on organ shortage more is required, because agreement rates do not necessarily translate into donation rates. Leaving aside the issue of quality, as the aim is also to make available organs of above average quality ${ }^{5}$, what matters most is the increase in organ donation after death or transplanted patients. When someone makes an active choice to register, this could be taken as expressing a strong and unambiguous willingness to donate. However, there is no guarantee that the donor's organs are suitable or that the family will not veto donation wishes. The problem of translating agreement rates into donation rates is more stringent when people are presumed donors by default. Passive agreements are ambiguous with reference to willingness to donate. When someone does not object to presumed donor status, this could be due to a willingness to donate, but it could also mean a lack of status awareness in the first place or a lack of interest for remote events. Additionally,

3 For more details, look up https://www.organdonation.nhs.uk/statistics/.

4 Using a multiple regression analysis, Johnson and Goldstein (2003) obtained roughly smaller results.

5 Available organs are many times below average quality. This has cumbersome implications for resource allocation policy, whether to use higher-risk organs in the more-urgent-need patients or to use higher-risk organs in the less-urgent-need patients. 
accepting a default is more often than not effortless, while changing it involves some costs. So, a decision not to object may be the result of personal comfort. The opacity of passive agreements with reference to donation preferences leaves room for family involvement to steer the decision either way. As a result, increases in consent rates through presumed agreements may not tell us much about what to expect with reference to actual donations. For example, some findings from experimental studies showed that nudge interventions increased registration rates, without affecting actual donation (Farrell 2015). Similarly, the presumed consent law that came into effect in Japan in 2010 has not increased numbers as expected. The rate of deceased organ donations has remained roughly the same even after the revision of the law (Soyama and Eguchi 2016).

Differences in registered donors between opt-out and opt-in legislations can be misleading and perceived as artificial if there is no significant difference in donated organs as well. Once we distinguish between donor status and donation per se, we get a messy picture about the impact of default policies on donation rates (Figure 1). There is no pattern suggesting that countries with presumed consent automatically outperform countries with explicit consent.

\begin{tabular}{llllll}
\hline $\begin{array}{l}\text { Legislation } \\
\text { type }\end{array}$ & Country & $\begin{array}{l}\text { 2012 rate } \\
\text { p.m.p. }\end{array}$ & $\begin{array}{l}\text { 2013 rate } \\
\text { p.m.p. }\end{array}$ & $\begin{array}{l}\text { 2014 rate } \\
\text { p.m.p. }\end{array}$ & $\begin{array}{l}\text { 2015 rate } \\
\text { p.m.p. }\end{array}$ \\
\hline Opt out & Spain & 87.6 & 88.8 & 90.2 & 100.7 \\
Opt out & Hungary & 34.1 & 38 & 52.4 & 48.4 \\
Opt out & Belgium & 93.9 & 87.9 & 83.4 & 87.3 \\
Opt out & Italy & 51.1 & 50.3 & 53.2 & 55.6 \\
Opt out & Finland & 55.7 & 50.7 & 62.4 & 67.8 \\
Opt out & France & 76.3 & 76.5 & 79.6 & 85.8 \\
Opt in & The Netherlands & 73.8 & 72.9 & 78.3 & 74.7 \\
Opt in & Denmark & 56.6 & 53.8 & 63.6 & 68.8 \\
Opt in & England & 65.1 & 73.2 & 71.8 & 69.6 \\
Opt in & Germany & 53.3 & 47.7 & 44.9 & 45.5 \\
Opt in & Romania & 11.9 & 19.2 & 20.3 & 17.7 \\
Opt in & Bulgaria & 2.6 & 5.4 & 11 & 10.0 \\
\hline
\end{tabular}

Figure 1. Annual rate of total number of patients transplanted. Data extracted from European Council Newsletter Transplant Vol. 21, 20, 19, 18).

Spain and Belgium, countries with opt-out legislation, have almost twice the donation rate of Germany and Denmark (opt-in legislation), but the Netherlands and England (opt-in models) have higher donation rates than Hungary, Italy, and Finland (opt-out models). Significant differences can also be seen between countries with the same 
legislation. For example, the Netherlands clearly outperforms other opt-in countries, while Spain has the highest donation rate among all opt-out countries. It seems that there are other background factors that explain these variations.

When we consider donation per se, it does not help too much to compare the registration rates of countries that have implemented an opt-out system with ones that have not. The variability of transplanted patients must be explained by other background factors that contribute to the overall outcome, such as medical and transplant infrastructure, special training, education level, propensity to donate or social norms, and religious beliefs about the use of postmortem bodies. Although it has an opt-in system, the US does better than other opt-out countries because of its superior medical system in matching donors with recipients, delivering the organs, and performing successful transplants (Thaler and Sunstein 2009). ${ }^{6}$ Spain has become the world leader mainly due to organizational measures. The Spanish model consists of earlier referral of possible donors to transplant coordination teams, a benchmarking project to identify critical success factors in donation after brain death, new family approach and care methods, the development of training courses aimed at specific groups of professionals, as well as national strategic plans (Matesanz et al. 2011).

Besides the relevance of medical infrastructure and organizational settings, there is a truth of the matter hard to digest and often omitted in public debate. Countries with low donation rates have, in general, a low mortality rate relevant for organ donation, while countries with high donation rates have higher mortality rates (Coppen et al. 2005). ${ }^{7}$ When controlled for mortality rates, there is no automatic superiority of opting-out systems. As it happens in organ donation, one man's tragedy is another man's salvation.

Moreover, there is a variability in policy application. The majority of countries with opt-out legislation, including the highest performer Spain, has adopted in practice what has been called a soft version of presumed consent. Doctors are still asking for family consent, even if the potential donor had not objected to presumed status during his/her lifetime (Rithalia et al. 2009). By contrast, in the hard version of presumed consent, organs can be used without family consultation. The lack of objection from a potential donor during his/her lifetime to the presumed donor status is sufficient. Now, if doctors still ask for family consent in presumed consent systems, this raises the question to what extent a soft version of opt-out systems understates the impact of defaults, as its objective is to bypass active choice as a means to increase organ

6 The reduced medical and transplant infrastructure could be a critical factor that explains why developing countries such as Romania and Bulgaria have low donation rates.

7 This raises a practical dilemma with thorny trade-offs. What should we do if the number of available organs are dependent on high mortality rates? Should we adopt policies that reduce the number of car accidents, for instance, but then we will have low donation rates? 
donation? Currently, there are not enough data to compare soft and hard versions of opt-out systems (Shepherd et al. 2014). To elucidate what factors contribute decisively to donated organs, future research will have to shed light on this issue. ${ }^{8}$

We should be cautious with predictions that opt-out legislation would increase organ donation by roughly $15 \%$. Analyses need to consider more relevant factors and how they interact in practice. The potential of opt-out systems to increase organ donation needs to be qualified in many respects if we want to avoid exaggerated expectations. It is overoptimistic to insist that small changes in default positions can have a big impact.

\subsection{Opt-out policy and consent standards}

What gives weight to opt-out policy is the argument that switching the default position from nondonor to donor can make a big difference in reducing organ shortage. Even if the opt-out policy may fall short for other ethical standards, it could still be regarded as morally permissible on grounds of promoting beneficence. In health-care settings, dilemmas in which one has to balance competing principles of beneficence and respect for autonomy are pervasive. This poses the question of how incompatible are defaults with consent standards.

Although explicit and presumed consent policies are different, Thaler and Sunstein argue that opting-out preserves freedom of choice by giving the opportunity to easily object $(2009,187)$. However, from the fact that a policy preserves freedom of choice, an adherence to consent requirements does not follow. Consent is thought to involve more than preserving freedom of choice. Imagine a company that subscribes you each day to a news magazine and, at the same time, it allows you to easily object to subscriber status. In this scenario, we still have the freedom to change the status. However, it does not follow that consent standards are being met, as they also require, in different contexts, seeking prior understanding from a subject or authorization for an intervention. The subscription case involves the freedom of opting out, but not an initial authorization of enlisting.

Describing opting-out policies as being based on presumed, implicit, or tacit consent is also confusing. These forms of consent make sense in particular contexts that we need to be aware of if we do not want to carry consent language too far. In clinical practice, consent is usually presumed on at least two conditions: a particular

8 At first sight, there seems to be very little difference in impact between opting-out and opting-in schemes as long as family members have in practice the power to veto. I suspect there is an important difference even if doctors are still asking for family consent in opt-out systems. This is because nudges are primarily about designing a choice context. The choice of seeking family consent is inescapable in opt-out systems, whereas in opt-in systems, doctors could easily side step the donation option. 
person cannot explicitly consent (for different reasons) and we presume something on the basis of available information about the personal history of that particular person. ${ }^{9}$ Implicit consent is inferred from previous commitments. When patients consent to surgery, it is also implied that they consent to other procedures that have not been specifically named in advance but which are necessary for the success of the medical intervention. Tacit consent is expressed when someone knowingly accepts a state of affairs by omitting to do something about it.

Given these standard forms of consent, the opt-out policy seems to be related to tacit consent, rather than to presumed or implicit consent. The attribution of donor default is not done on the basis of available information about the values and preferences of citizens, nor is it inferred from their previous commitments. It is more like assigning a status that is tacitly confirmed by omitting to object. ${ }^{10}$ But even this framing of consent is problematic since tacit consent is dependent on prior knowledge of the state of affairs, which is generated by omitting to act. The opt-out legislation does not satisfy this condition. If the lack of objecting to a donor default is to express tacit consent, then we must have evidence that all citizens are aware and understand the policy. However, obtaining such evidence is extremely hard. Public information campaigns can raise awareness, but they cannot guarantee, on a countrywide scale, the standards that are needed for valid tacit consent. ${ }^{11}$

Current opt-out legislations are based on loose talk of consent as it does not align well with standard requirements of presumed, implicit, and tacit consent. And the fact that opting out opposes explicit consent is considered sufficient to settle its moral permissibility. The complicated empirical question about its impact on donation rates will have to be bracketed if the opt-out policy fails the normative test of explicit consent. There is a strong intuition that at least in health-care settings "consent should refer to an individual's actual choices, not to presumptions about the choices the individual would or should make" (Beauchamp and Childress 2001, 66). The use of the opt-out policy is widely viewed as morally suspicious, especially because it bypasses our rational capacities and actual choices (Saghai 2013; MacKay and Robinson 2016; Levy 2017).

9 Consent is also thought to be presumed on the basis of a theory of rationality, labeled in philosophical ethics as rational consent. This way of thinking about presumed consent is not influential in clinical practice.

10 Some defenders of the opt-out scheme admit that the label "presumed consent" is confusing but insist on justifying it by appealing to implicit consent (refer Saunders 2012).

11 It remains an open question whether on a countrywide scale, the standards of evidence for tacit consent should be different from those for individual cases. One could argue that population surveys that show awareness over an absolute majority threshold constitute evidence for consent. The issue is whether it properly counts as sufficient evidence for consent or more is needed. 


\subsection{Beyond the dichotomy of presumed and explicit consent}

The insistence on nudges that capitalize on attributing a presumed status without prior interaction encourages a misleading picture. Once it is clarified that nudges are primarily concerned with the architecture of choice, we see that behavioral interventions are not inherently opposed to explicit consent. The focus on opt-out forms of intervention overlooks the diversity and potential versatility of nudges to comply with consent requirements, encourage autonomous decisions, engage deliberative capacities, and reduce the costs of active choice.

We often do not form preferences on particular issues simply because they are not close enough to our immediate choice context. The question of what could happen with our organs after we die or whether we are saving enough for retirement is not something that grips our daily lives. Most probably we do not bother that much if there is no urgency. Add to this our daily inertia and routines, and it is not surprising that people fail to act, even according to their own preferences. This is where choice architects intervene. The aim is to make choosing easier when it is time consuming or cognitively demanding in searching for information. The strategy is to intervene in how people's possible choices are arranged. We nudge someone when we arrange his/her choice context in order to influence the likelihood of choosing option (A) over option (B), even though it would still be easy to choose (B), and (A) is not worse than (B). We also nudge someone when we simply introduce options that are rarely considered in his/her choice context.

This is not incompatible with explicit consent requirements because nudging interventions do not necessarily have to bypass actual choices in order to influence decision-making. The only dissimilarity between conditions in the study by Johnson and Goldstein was not presumed consent versus explicit consent, but the contrast between confirming a donor status and confirming a nondonor status. Thus, reasons that explain nudging effects could equally work within an explicit consent framework. A nudge is supposed to work because decision-makers perceive defaults as reasonable recommendations. If the perception of reasonable recommendations is what sways people to accept the status quo, then it does not matter that much how we frame the consent requirements. Instead of waiting for people to object to donor status, we could explicitly ask them, when they interact with public institutions, whether they would like to confirm or change the status quo. ${ }^{12}$ In addition, filling out many forms or perceived bureaucracy can discourage people to sign in as donors, while accepting a default is effortless. Consequently, we achieve a nudging effect when we make registration as easy as possible, ideally at a mouse click.

12 Default effects persist even when people are informed of the presence of default options (Loewenstein et al. 2015). 
Note that in Johnson and Goldstein's study, the neutral condition, which does not stipulate a default option, was just as effective in obtaining consent rates (79\%) as the opt-out condition (82\%), compared with the opt-in condition (42\%). "Neutral condition" is a misleading label. It makes us overlook its nudging effect, which works by intervening in a choice context just to introduce options that are not of immediate concern for people in their daily life. This implies that the consent rate can be improved by presenting people a donation option when, for instance, they get a driver license, change their ID, or undergo a routine medical checkup.

Another tool of choice architecture compatible with explicit consent is the provision of relevant information that does not usually lie around. Thaler and Sunstein $(2009,190)$ describe the case of Illinois in the US. In promoting organ donation, the State of Illinois highlighted how many people are on the waiting list, as well as the fact that $87 \%$ of adults in Illinois believe that registering as an organ donor is the right thing to do. In the same manner, the introduction of a donation option in choice contexts can go together with information about the importance of the problem, evaluative attitudes, and results. This tool encourages autonomous decisions by providing relevant information. It assumes that, when given the possibility, people will lean more toward informed choices, understood as responsive to relevant facts, and morally desirable outcomes.

Furthermore, there are cases in which questionable beliefs negatively influence the willingness to donate. In Turkey, people are most likely to refuse organ donation for religious reasons (29\%). Other countries where people are more likely to be reluctant to donate organs for religious reasons are Romania (17\%), Austria (15\%), Macedonia (12\%), and Slovakia (11\%). ${ }^{13}$ But what is striking is that the religious beliefs are contrary to positions held by the Orthodox and Catholic churches, as well as by Islam. All support organ donation with therapeutic aims, as a sign of kindness and love for fellow human beings. In such cases, a donation option could be presented along with information about the support from religious institutions, leading figures, or holy texts. Nudges such as these can make people self-conscious regarding the epistemic status of their religious beliefs. The hope of providing relevant information and prompting deliberative capacities is a revision of spurious beliefs. This type of intervention can be applied to family interviews, as well as other behavioral interventions that nudge families toward more deliberative decisions. ${ }^{14}$

13 Among Europeans, fear of manipulation of the human body and distrust in the system are the most prevailing reasons for not donating organs (refer Special Eurobarometer 333a 2010, 26).

14 A study in a French organ procurement centre (Le Nobin et al. 2014) documented that the most frequent reason for family refusal was the desire to keep the body's wholeness (46.3\%), followed by religious opposition (16.4\%). Doctors could make family members aware of false beliefs, cognitive bias, and misunderstanding and thereby shift involved parties toward a more-reflective frame of mind (Shaw and Elger 2014; Stefanescu Schmidt et al. 2017). 


\subsection{Nudging beyond potential donors}

Dubious talk of consent relating to the opting-out policy and its contrast with explicit agreement fueled charges that it poses threats to people's autonomy. But as I have argued, nudging interventions can be made compatible with explicit consent requirements. Rerouting nudges away from presumed consent could also have benefits for family involvement in postmortem decision-making. Because presumed consent is ambiguous with reference to willingness to donate, obtaining actual choices to donate could provide more moral authority to families to fulfill one's wishes.

Refocusing the potential of behavioral insights can go even further than private citizens and family members. How medical institutions perform is essential for increasing donation rates. Ultimately, nudging advocates believe in better governance (Thaler and Sunstein 2009; Halpern 2016). The moral advantage of targeting individuals acting on behalf of public institutions is that concerns applicable to private citizens do not hold for public servants. Doctors, by their very professional identity and institutional context, are already committed to forgo options, which are at liberty for private individuals, and accept interventions to achieve public goods.

So, it is natural to look more into how we could nudge relevant parties to perform better according of their own mission. Applications of behavioral insights from other medical challenges can serve as paradigms that could guide future research. For instance, there is a widespread use of antibiotics to treat infections for which it has little clinical advantage, killing beneficial bacteria as well (Steinman et al. 2003; Blaser 2011). Many interventions have been used to reduce unnecessary prescription of antibiotics, such as physician and patient education or computerized clinical decision support, but in a recent investigation, Meeker et al. (2016) implemented insights from behavioral research in primary care practices. One nudging intervention was peer comparison. Clinicians with the lowest unnecessary prescribing rates were informed monthly that they were "top performers". Clinicians with higher rates received monthly e-mails, which included the number and proportion of their antibiotic prescriptions for antibiotic-inappropriate infections, alongside the proportion of top performers. Compared with baseline period, the intervention period reduced the rate of unnecessary prescriptions from $35 \%$ to $19.2 \%$. In another randomized controlled trial, social norm feedback from a high-profile messenger substantially reduced antibiotic prescribing (Hallsworth et al. 2016). The intervention consisted of sending a letter from England's Chief Medical Officer and a leaflet on antibiotics for use with patients to general practitioners. The letter described how the practice was prescribing antibiotics at a higher rate than $80 \%$ of practices in its local area.

Similarly, donation rates could be increased by nudging specific groups of professionals through interventions such as peer comparison and social norm feedback from a high-profile messenger. Indeed, the issue of overuse of antibiotics and that of organ shortage are quite different. Antibiotic prescription is incumbent on the doctor's decision, whereas organ donation is not. While it is true that because of 
this asymmetry, we cannot expect similar results, the central point of these examples is to illustrate how nudging applications could potentially target individuals acting on behalf of public institutions as well. It is a mistake to think that the contribution of medical professionals to increase organ donation is not subject to unwanted institutional inertia, social influences, or cognitive biases.

\subsection{Conclusion}

In effect, $99.9 \%$ of French citizens are presumed donors, compared to $4.25 \%$ of Danish citizens who have actively chosen to become donors. Understandably, the proposal to move toward opting-out systems is attractive, as it promises a big impact with small changes in default positions. However, these huge differences in registration rates are potentially misleading. Countries with opt-out schemes do not automatically outperform those with opt-in schemes in terms of actual donation rates. The contribution of opt-out systems to increase organ donation needs to be qualified in many aspects if we want to avoid false expectations. Additionally, there are normative issues. Current opt-out legislations are based on confusing talk of presumed, implicit, or tacit consent. The attribution of donor default is neither done on the basis of available information about the values and preferences of citizens, inferred from their previous commitments, nor is it dependent on prior knowledge of the state of affairs that is generated by omitting to act. And, especially, the fact that opting-out bypasses explicit consent is widely considered a decisive reason against it. But we need not use nudges only as tools of bypassing actual choices. The insistence on opt-out forms of intervention overlooks the diversity and versatility of nudges to comply with explicit consent standards and encourage autonomous decisions. Behavioral interventions can be refocused to make the actual choosing of potential donors easier when it is time consuming and cognitively demanding, and when the options are outside people's normal choice architecture. These interventions can have a much wider application, such as nudging family members toward more deliberative decisions during consent interviews, as well as inducing medical professionals to perform better as per their own mission. ${ }^{15}$

\section{References}

Abadie, Alberto, and Sebastien Gay. 2006. "The impact of presumed consent legislation on cadaveric organ donation: a cross-country study.” Journal of health economics 25(4): 599-620.

15 I thank Mihaela Frunză, Dorina Pătrunsu, Reinhard Merkel, Blanca Rodríguez López, Emanuel Socaciu, Constantin Vică, Cristina Voinea, Toni Gibea, and Wangmo Tenzin for comments that improved this chapter. 
Beauchamp, Tom, and James Childress. 2001. Principles of biomedical ethics. New York: Oxford University Press.

Blaser, Martin. 2011. "Antibiotic overuse: stop the killing of beneficial bacteria." Nature 476(7361): 393-394.

Coppen, Remco, Friele, Roland D., Marquet, Richard L., and Sjef K. M. Gevers. 2005. "Opting-out systems: No guarantee for higher donation rates.” Transplant international, 18(11), 1275-1279.

Farrell, Anne-Maree. 2015. "Addressing organ shortage: are nudges the way forward?" Law, Innovation and Technology 7(2): 253-282.

Gigerenzer, Gerd. 2008. “Moral intuition = fast and frugal heuristics?" In W. Sinnott-Armstrong (Ed.), Moral Psychology: Vol 2. The cognitive science of morality: Intuition and diversity. Cambridge, Massachusetts: MIT Press.

Halpern, David. 2016. Inside the Nudge Unit: How small changes can make a big difference. London: Penguin Random House

Hallsworth, Michael, Chadborn, Tim, Sallis, Anna, Sanders, Michael, Berry, Daniel, Greaves, Felix, Clements, Lara, and Sally C. Davies. 2016. "Provision of social norm feedback to high prescribers of antibiotics in general practice: a pragmatic national randomised controlled trial." The Lancet, 387(10029): 1743-1752.

Johnson, Eric, and Daniel Goldstein. 2003. “Do defaults save lives?” Science 302(5649): 1338-1339.

Le Nobin, Julien, Pruvot, Francois-Rene, Villers, Arnauld, Flamand, Vincent, and Sebastien Bouye. 2014. "Family refusal of organ donation: a retrospective study in a French organ procurement center." Progres en urologie: journal de l'Association francaise d'urologie et de la Societe francaise d'urologie 24(5): 282-287.

Levy, Neil. 2017. "Nudges in a post-truth world". Journal of medical ethics 43:495-500.

Loewenstein, George, Bryce, Cindy, Hagmann, David, and Sachin Rajpal. 2015. "Warning: You are about to be nudged." Behavioral Science \& Policy 1(1): 35-42.

Matesanz, Rafael, Domínguez-Gil, Beatriz, Coll, Elisabeth, de la Rosa, Gloria, and Rosario Marazuela. 2011. "Spanish experience as a leading country: what kind of measures were taken?" Transplant International 24(4): 333-343.

MacKay, Douglas, and Alexandra Robinson. 2016. "The ethics of organ donor registration policies: Nudges and respect for autonomy." The American Journal of Bioethics 16(11): 3-12.

Meeker, Daniella, Linder JA, Fox CR, Friedberg MW, Persell SD, Goldstein NJ, Knight TK, Hay JW, and Doctor JN. 2016. "Effect of behavioral interventions on inappropriate antibiotic prescribing among primary care practices: a randomized clinical trial." JAMA 315(6): 562-570.

Newsletter Transplant Vol. 21, No 1 Sept. 2016.

Newsletter Transplant Vol. 20, No 1 Sept. 2015.

Newsletter Transplant Vol. 19, No 1 Sept. 2014.

Newsletter Transplant Vol. 18, No 1 Sept. 2013.

Richards, Janet Radcliffe. 2012. The ethics of transplants: Why careless thought costs lives. New York: Oxford University Press.

Rithalia, Amber, McDaid, Catriona, Suekarran, Sara, Myers, Lindsey, and Amanda Sowden. 2009. "Impact of presumed consent for organ donation on donation rates: a systematic review." $B M J$ 338: a3162.

Rodriguez-Arias, David, and Myfanwy Morgan. 2016. “'Nudging' Deceased Donation Through an Opt-Out System: A Libertarian Approach or Manipulation?" The American Journal of Bioethics 16(11): 25-28.

Romanian Ministry of Health Order 1158/2012.

Saghai, Yashar. 2013. "Salvaging the concept of nudge." Journal of medical ethics 39(8): 487-493. Saunders, Ben. 2012. "Opt-out organ donation without presumptions." Journal of medical ethics 38(2): 69-72. 
Shaw, David. 2014. "Organ donation after assisted suicide: a potential solution to the organ scarcity problem.” Transplantation 98(3): 247-251.

Shaw, David, and Bernice Elger. 2014. "Persuading bereaved families to permit organ donation." Intensive care medicine 40(1): 96-98.

Shepherd, Lee, O’Carroll, Ronan E., and Eamonn Ferguson. 2014. “An international comparison of deceased and living organ donation/transplant rates in opt-in and opt-out systems: a panel study." BMC medicine 12(1): 131.

Soyama, Akihiko, and Susumu Eguchi. 2016. "The current status and future perspectives of organ donation in Japan: learning from the systems in other countries.” Surgery today 46(4): 387-392.

Special Eurobarometer 333a. 2010. Organ donation and transplantation.

Stefanescu Schmidt, Ada C. Bhatt, Ami and Cass Sunstein R. 2017. “Boundedly Rational Patients? Health and Patient Mistakes in a Behavioral Framework.” Available at SSRN: https://ssrn.com/ abstract $=2953250$

Steinman, Michael A., Gonzales, Ralph, Linder, Jeffrey A., and C. Seth Landefeld. 2003. "Changing use of antibiotics in community-based outpatient practice, 1991-1999." Annals of Internal Medicine 138(7): 525-533.

Sunstein, Cass. 2014. “Nudging: a very short guide.” Journal of Consumer Policy 37(4): 583-588.

Thaler, Richard, and Cass Sunstein. 2009. Nudge: Improving decisions about health, wealth, and happiness. London: Penguin Books.

Vlăducu, Andrei, Diaconu, D, Dobre, Dani, and B. Deaconu. 2016. "Status-quo și donarea de organe în România. Un studiu descriptiv cantitativ.” Revista de Psihologie 62(1): 45-56.

U.S. Department of Health and Human Services. 2013. National Survey of Organ Donation Attitudes and Behaviors.

Wilkinson, Dominic, and Julian Savulescu. 2012. "Should we allow organ donation euthanasia? Alternatives for maximizing the number and quality of organs for transplantation." Bioethics 26(1): 32-48.

Wu, Jun, Platero-Luengo, Aida, Sakurai, Masahiro, Sugawara, Atsushi, Gil, Maria Antonia, Yamauchi, Takayoshi, Suzuki, Keiichiro, Bogliotti, Yanina Soledad, Cuello, Cristina, and Mariana Morales Valencia. 2017. “Interspecies Chimerism with Mammalian Pluripotent Stem Cells.” Cell 168(3): 473-486. 